\title{
Genome-scale analysis of anaerobic benzoate and phenol metabolism in the hyperthermophilic archaeon Ferroglobus placidus
}

\author{
Dawn E Holmes ${ }^{1,2,3}$, Carla Risso ${ }^{1,3}$, Jessica A Smith ${ }^{1}$ and Derek R Lovley ${ }^{1}$ \\ ${ }^{1}$ Department of Microbiology, University of Massachusetts Amherst, Amherst, MA, USA and ${ }^{2}$ Department \\ of Physical and Biological Sciences, Western New England College, Springfield, MA, USA
}

\begin{abstract}
Insight into the mechanisms for the anaerobic metabolism of aromatic compounds by the hyperthermophilic archaeon Ferroglobus placidus is expected to improve understanding of the degradation of aromatics in hot $\left(>80^{\circ} \mathrm{C}\right)$ environments and to identify enzymes that might have biotechnological applications. Analysis of the $F$. placidus genome revealed genes predicted to encode enzymes homologous to those previously identified as having a role in benzoate and phenol metabolism in mesophilic bacteria. Surprisingly, $F$. placidus lacks genes for an ATP-independent class II benzoyl-CoA (coenzyme A) reductase (BCR) found in all strictly anaerobic bacteria, but has instead genes coding for a bzd-type ATP-consuming class I BCR, similar to those found in facultative bacteria. The lower portion of the benzoate degradation pathway appears to be more similar to that found in the phototroph Rhodopseudomonas palustris, than the pathway reported for all heterotrophic anaerobic benzoate degraders. Many of the genes predicted to be involved in benzoate metabolism were found in one of two gene clusters. Genes for phenol carboxylation proceeding through a phenylphosphate intermediate were identified in a single gene cluster. Analysis of transcript abundance with a whole-genome microarray and quantitative reverse transcriptase polymerase chain reaction demonstrated that most of the genes predicted to be involved in benzoate or phenol metabolism had higher transcript abundance during growth on those substrates vs growth on acetate. These results suggest that the general strategies for benzoate and phenol metabolism are highly conserved between microorganisms living in moderate and hot environments, and that anaerobic metabolism of aromatic compounds might be analyzed in a wide range of environments with similar molecular targets.

The ISME Journal (2012) 6, 146-157; doi:10.1038/ismej.2011.88; published online 21 July 2011

Subject Category: integrated genomics and post-genomics approaches in microbial ecology

Keywords: Archaea; benzoate; hyperthermophiles; phenol; transcriptomics
\end{abstract}

\section{Introduction}

Ferroglobus placidus is the only hyperthermophilic microorganism and the only member of the Archaea that is known to be capable of anaerobically oxidizing aromatic compounds. F. placidus can grow by oxidizing benzoate and phenol to carbon dioxide with $\mathrm{Fe}(\mathrm{III})$ serving as the sole electron acceptor (Tor and Lovley, 2001).

It has been speculated that the anaerobic metabolism of aromatic compounds may be an important part of the carbon cycle in hot $\left(>80^{\circ} \mathrm{C}\right)$ environments (Kashefi et al., 2000; Tor et al., 2001). Aromatic compounds have been detected in sediments associated with hydrothermal vent sites and

Correspondence: DE Holmes, Department of Physical and Biological Sciences, Western New England College, 1215 Wilbraham Road, Springfield, MA 01119, USA.

E-mail: dholmes@microbio.umass.edu

${ }^{3}$ These authors contributed equally to this work.

Received 21 December 2010; revised 7 June 2011; accepted 7 June 2011; published online 21 July 2011 petroleum reservoirs (Simoneit and Lonsdale, 1982; Bazylinski et al., 1989; Mangani et al., 1991; Goetz and Jannasch, 1993; Magot et al., 2000; Culotta et al., 2007). Previous studies have also shown that benzoate can be oxidized to ${ }^{14} \mathrm{CO}_{2}$ in hot sediments from the same general location in Vulcano, Italy, where F. placidus was isolated (Hafenbradl et al., 1996; Tor and Lovley, 2001). Although sulfate reduction appeared to be the predominant terminal electron-accepting process in those sediments, additions of molybdate, which inhibited sulfate reduction, did not inhibit benzoate oxidation. These results suggested that benzoate oxidation in the sediments might be coupled to $\mathrm{Fe}(\mathrm{III})$ reduction, which was also a minor, but detectable, electronaccepting process in the sediments.

The metabolism of benzoate has been studied intensively in members of mesophilic Bacteria (Harwood et al., 1999; Gibson and Harwood, 2002; Boll, 2005; Carmona et al., 2009). In all anaerobic benzoate-degrading bacteria that have been studied to date, the enzyme benzoate-CoA (coenzyme A) 


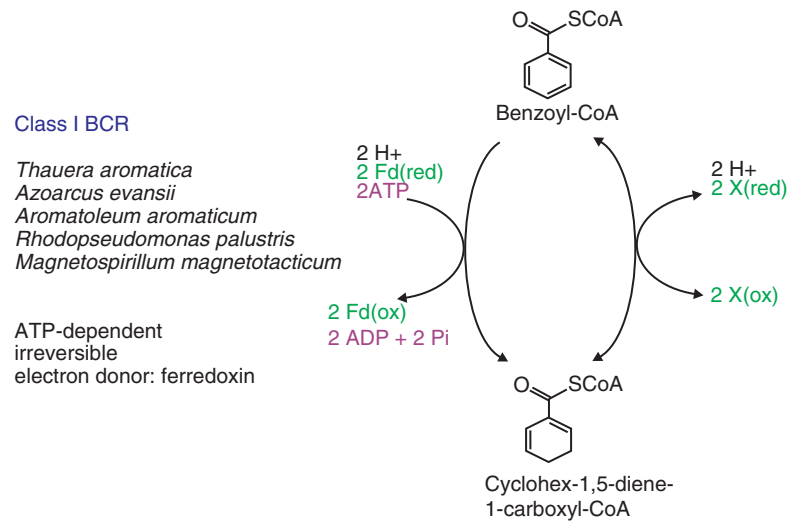

Class II BCR

Geobacter metallireducens Geobacter bemidjiensis Geobacter daltonii

Syntrophus aciditrophicus

Desulfococcus multivorans

Desulfotomaculum gibsoniae

ATP-independent

reversible

electron donor: unknown

1-carboxyl-CoA

Figure 1 The two classes of benzoyl-CoA reductases previously described in facultative and strictly anaerobic organisms. Fd, ferredoxin; Ox, oxidized; Red, reduced.

ligase (BCL) first catalyzes the conversion of benzoate to benzoyl-CoA. The next step is the reduction of the aromatic ring to cyclohex-1,5-diene-1-carboxylCoA by benzoyl-CoA reductase (BCR). Two different types of BCR have been described (Figure 1). Class I BCR complexes are composed of four subunits, and accept electrons from a reduced ferredoxin protein. This reaction is ATP dependent and appears to be irreversible (Boll and Fuchs, 1995). The best-studied class I BCRs include those from the facultative denitrifying species Thauera aromatica (Boll and Fuchs, 1995), Azoarcus spp. (Lopez Barragan et al., 2004) and the phototroph Rhodopseudomonas palustris (Egland et al., 1997).

A diversity of strict anaerobic microorganisms such as Geobacter species (Wischgoll et al., 2005; Butler et al., 2007), Syntrophus aciditrophicus (Elshahed and McInerney, 2001) and Desulfococcus multivorans (Peters et al., 2004) have a class II BCR. The reaction catalyzed by this complex is reversible and ATP independent (Kung et al., 2009, 2010; Löffler et al., 2010). It has been proposed that strict anaerobes must use class II BCRs because the amount of energy available from benzoate oxidation coupled to the reduction of Fe(III), sulfate or protons is not sufficient to support the substantial energetic requirement of the ATP-dependent class I BCR reaction (Schöcke and Schink, 1999; Kung et al., 2009, 2010; Löffler et al., 2010).

Both classes of BCR complexes produce cyclohex1,5-diene-1-carbonyl-CoA (Figure 1), which is then metabolized through a series of reactions (addition of a molecule of water to a double bond, dehydrogenation and hydrolytic ring cleavage) that generate $\mathrm{a} \mathrm{C}_{7}$-dicarboxyl-CoA compound. Two slightly different versions of these reactions have been described (Figure 2): the BadK-BadH-BadI pathway found in the phototroph R. palustris (Harwood et al., 1999; Gibson and Harwood, 2002) and the Dch-Had-Oah pathway (Breese et al., 1998) found in all other benzoate-degrading organisms studied to date (Carmona et al., 2009). The ultimate fate of this $\mathrm{C}_{7}$-dicarboxyl-CoA compound is to be converted into acetyl-CoA by $\beta$-oxidation, either to be fully oxidized to $\mathrm{CO}_{2}$ by the tricyclic acids cycle or to be used in anabolic reactions.

The anaerobic degradation of aromatic compounds other than benzoate requires a series of reactions that convert them into the central metabolite of the pathway, benzoyl-CoA (Harwood et al., 1999; Carmona et al., 2009). In the case of phenol, two different pathways have been proposed (Figure 3). Several denitrifying species from the genera Pseudomonas, Azoarcus and Thauera, as well as the Fe(III) reducer, Geobacter metallireducens, initially phosphorylate phenol to phenylphosphate, which is then carboxylated to produce 4-hydroxybenzoate (Lack and Fuchs, 1994; Breinig et al., 2000; Rabus et al., 2005; Schleinitz et al., 2009). Clostridium hydroxybenzoicum, on the other hand, directly carboxylates phenol to 4-hydroxybenzoate (Zhang and Wiegel, 1994). Once 4-hydroxybenzoate has been formed by one of these two pathways, it is then converted to benzoyl-CoA via the sequential action of 4-hydroxybenzoate-CoA ligase (Merkel et al., 1989) and 4-hydroxybenzoylCoA reductase (Gibson et al., 1997).

The recent availability of the complete genome of F. placidus (http://genome.ornl.gov/microbial/fpla/) has made it feasible to evaluate the mechanisms for monoaromatic metabolism in this organism. The results presented here suggest that $F$. placidus metabolizes benzoate and phenol via pathways that are similar to those commonly found in Bacteria, but surprisingly does not possess the class II BCR complex, which has previously been considered to be common to strict anaerobes.

\section{Materials and methods}

Growth of F. placidus

F. placidus strain AEDII12DO (DSM 10642) was obtained from the type culture collection of the Deutsche Sammlung von Mikroorganismen and Zelkuturen, Braunschweig, Germany. Strict anaerobic 


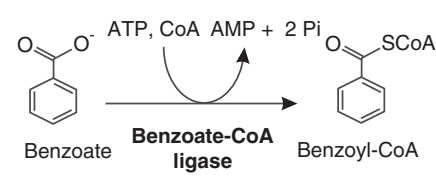

BCL1: Fer_1044 (4.06/7.46) (2.73/3.41)

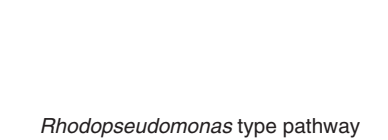

Cyclohex-1-ene
-1-carboxyl-CoA hydratase
BadK: Ferp_1035 (4.66/4.87) (3.20/5.28)

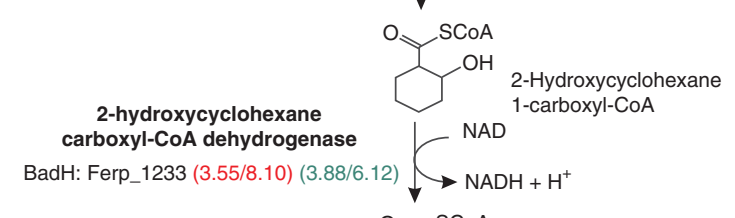

O $S C O A$

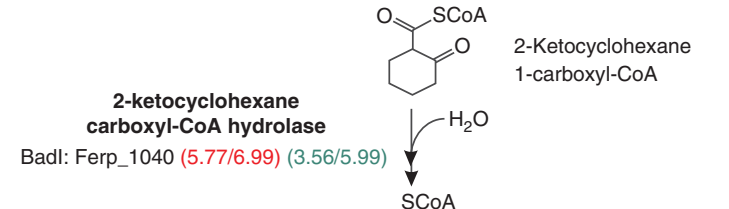

pimC: Ferp_1566(ND/1.07) (ND/1.97)

pimD: Ferp_1579 (2.59/2.59) (ND/2.06)

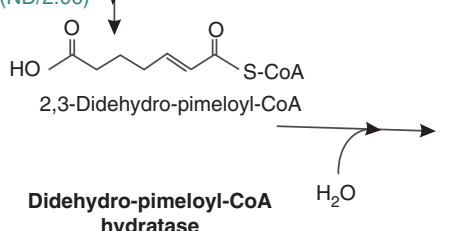

hydratase

Dph: Ferp_1031 (3.84/4.74) (6.53/10.30)
$B z d N O P Q+f d x$

BzdN: Ferp_1184 (5.26/10.48) (5.96/6.98)

BzdO: Ferp_1185 (2.90/7.21) (2.82/5.43)

BzdP: Ferp_1186 (7.32/12.07) (6.48/8.80)

BzdQ: Ferp_1187 (2.38/3.65) (3.62/7.03)

$f d x$ ?: Ferp_1180 (5.18/9.75) (5.63/9.81)

Cyclohexa-1,5-diene-1-

carbonyl-CoA hydratase (Dch)

4 Thauera-Azoarcus type pathway

6-Hydroxycyclohex-1

NAD 6-hydroxycyl-carboxyl-CoA

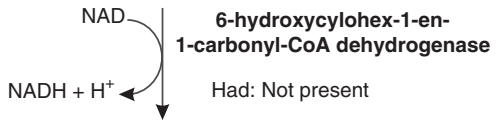

$\mathrm{O} \mho_{\mathrm{SCOA}}$ 6-Ketocyclohex-1-ene

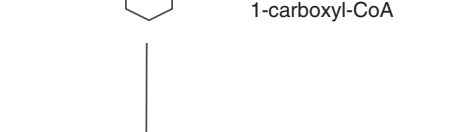

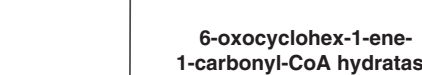

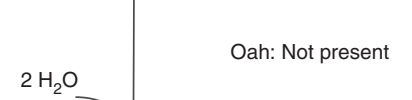

Figure 2 Pathways previously proposed for anaerobic benzoate degradation in bacteria and genes in $F$. placidus predicted to encode homologous proteins. The numbers next to the gene designations represent the fold-change in transcript abundance determined with microarray (first number) or qRT-PCR (second number) analyses in benzoate- (red) or phenol- (green) grown cells vs acetate-grown cells.

culturing and sampling techniques were used throughout (Miller and Wolin, 1974; Balch et al., 1979). F. placidus cells were grown with acetate (10 mM), benzoate $(1 \mathrm{mM})$ or phenol $(0.5 \mathrm{mM})$ as the electron donor, and $\mathrm{Fe}(\mathrm{III})$ citrate $(56 \mathrm{~mm})$ as the electron acceptor.

F. placidus medium was prepared as previously described (Tor and Lovley, 2001). After autoclaving, $\mathrm{FeCl}_{2}(1.3 \mathrm{mM}), \mathrm{Na}_{2} \mathrm{SeO}_{4}\left(30 \mu \mathrm{gl}^{-1}\right), \mathrm{Na}_{2} \mathrm{WO}_{4}\left(40 \mu \mathrm{gl}^{-1}\right)$, APM salts $\left(1 \mathrm{gl}^{-1} \mathrm{MgCl}_{2}, 0.23 \mathrm{gl}^{-1} \mathrm{CaCl}_{2}\right.$ ) (Coates et al., 1995), DL vitamins (Lovley and Phillips, 1988) and all electron donors were added to the sterilized medium from anaerobic stock solutions. Cultures were incubated under $\mathrm{N}_{2}: \mathrm{CO}_{2}(80: 20)$ at $85^{\circ} \mathrm{C}$ in the dark.

\section{Analytical techniques}

Concentrations of benzoate, phenol and phenylphosphate were determined with high performance liquid chromatography (Agilent 1100 HPLC Series, Santa Clara, CA, USA), with an Altima HP C18 HL column. The eluent consisted of $\mathrm{MeOH}-\mathrm{H}_{2} \mathrm{O}$ (60:40) and $0.1 \% \mathrm{H}_{3} \mathrm{PO}_{4}$ and the compounds were detected at an absorbance of $280 \mathrm{~nm}$

Phenylphosphate, an intermediate from anaerobic phenol degradation, was also detected with thin layer chromatography. Phenol-grown cells were harvested by centrifugation $(10500 \mathrm{~g} ; 10 \mathrm{~min})$ and the supernatant was filtered with a $0.2 \mu \mathrm{m}$ filter. Approximately $30 \mu \mathrm{l}$ of the supernatant was then loaded onto Whatman flexible plates $(250 \mathrm{~m}$ layer $\mathrm{Al} / \mathrm{Sil} \mathrm{G} / \mathrm{UV}$ ), $1 \mu \mathrm{l}$ at a time, and the intermediates were separated with a solvent consisting of ethanol/dichloromethane/ $\mathrm{H}_{2} \mathrm{O}(8: 1: 1)$ as previously described (Lack and Fuchs, 1994; Schleinitz et al., 2009). The separated compounds were then visualized on an ultraviolet light box. 


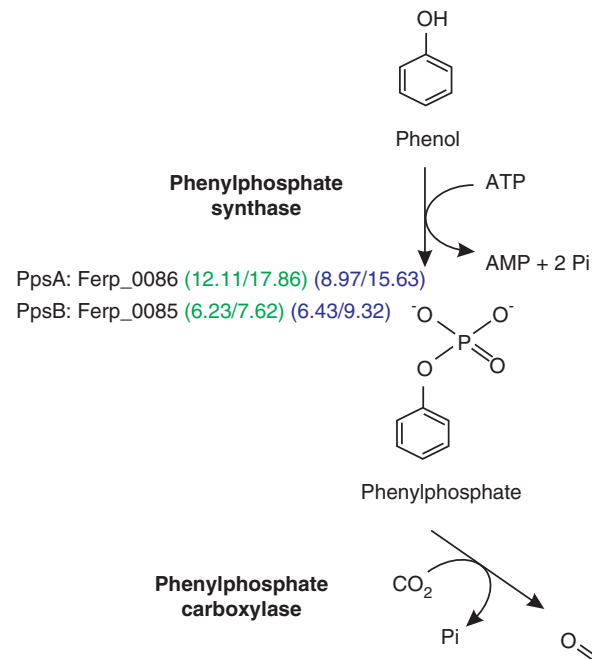

PpcB: Ferp_0089 (4.85/10.02) (5.89/8.13)
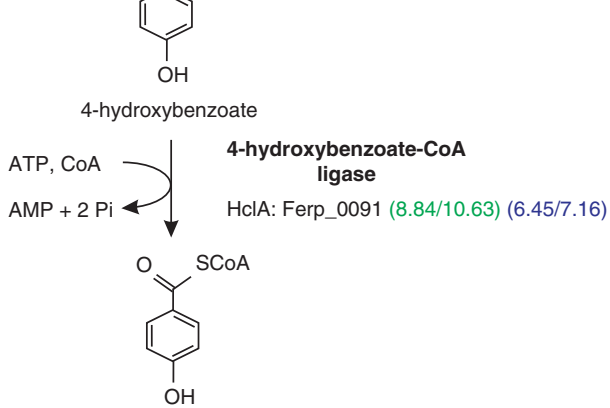

4-hydroxybenzoyl-CoA
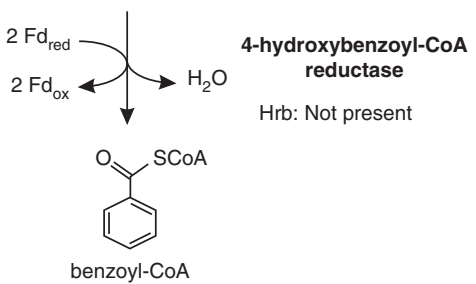

Figure 3 Pathways previously proposed for anaerobic phenol degradation in bacteria and genes in F. placidus predicted to encode homologous proteins. The numbers next to the gene designations represent the fold-change in transcript abundance of phenol-grown cells vs acetate- (green) or benzoate- (blue) grown cells determined with microarray (first number) and qRT-PCR (second number) analyses.

\section{Operon organization and gene annotation}

Operon organization of the F. placidus genome was predicted using the commercial version of the FGENESB software (V Solovyev and A Salamov, unpublished data; Softberry Inc., Mount Kisco, NY, USA; 2003-2009), as previously described for the genomes of various Geobacteraceae (Krushkal et al., 2007; Mahadevan et al., 2008; Tran et al., 2008). Sequence parameters used in Markov chain-based modeling of protein-coding genes were estimated by FGENESB via an iterative procedure using the sequence of each genome and a minimum ORF length of $100 \mathrm{bp}$.

\section{Extraction of RNA from samples}

RNA for microarray and quantitative reverse transcriptase polymerase chain reaction (qRT-PCR) analyses was extracted during exponential growth of $F$. placidus on benzoate, acetate and phenol. $F$. placidus exhibits different growth rates on these three compounds. Based on previously reported data, the doubling times were $45 \mathrm{~h}$ for acetate, $63 \mathrm{~h}$ for benzoate and $71 \mathrm{~h}$ for phenol (Tor et al., 2001; Tor and Lovley, 2001). In all cases, triplicate RNA samples were extracted during exponential growth.

For extraction of RNA, cultures $(100 \mathrm{ml}$ in $156 \mathrm{ml}$ serum bottles) were divided into $50 \mathrm{ml}$ conical tubes (Falcon, BD Biosciences, Bedford, MA, USA), and cells were pelleted by centrifugation at $3000 \mathrm{~g}$ for 15 min. Pellets were then immediately frozen in liquid nitrogen and stored at $-80^{\circ} \mathrm{C}$.

The pellets were resuspended in $10 \mathrm{ml} \mathrm{HG}$ extraction buffer preheated to $65^{\circ} \mathrm{C}$. The HG extraction buffer consisted of $100 \mathrm{~mm}$ Tris-HCl, $\mathrm{pH} 8$; $100 \mathrm{mM} \mathrm{NaCl} ; 10 \mathrm{~mm}$ EDTA; $2.5 \%$-mercaptoethanol, 
$1 \%$ sodium dodecyl sulfate, $2 \%$ Plant RNA Isolation Aid (Ambion, Woodward, TX, USA); $5 \mathrm{mM}$ ascorbic acid; Proteinase $\mathrm{K}\left(0.6 \mathrm{mg} \mathrm{ml}^{-1}\right)$ and lysozyme $\left(5 \mathrm{mg} \mathrm{ml}^{-1}\right)$. The suspended cells were then dispersed into $102 \mathrm{ml}$ screw cap tubes and incubated at $65^{\circ} \mathrm{C}$ for $10 \mathrm{~min}$. After incubation, samples were placed on ice, and $2 \mu \mathrm{l}$ Superase-In (Ambion) and $0.025 \mathrm{mM} \mathrm{CaCl}{ }_{2}$ were added. Samples were then centrifuged at $16100 \mathrm{~g}$ for $10 \mathrm{~min}$, and the supernatant was transferred to new $2 \mathrm{ml}$ screw cap tubes. A measure of $50 \mu \mathrm{l}$ Plant RNA Isolation Aid (Ambion), $4 \mu \mathrm{l}$ linear acrylamide ( $5 \mathrm{mg} \mathrm{ml}^{-1}$; Ambion), $600 \mu \mathrm{l}$ of hot acidic phenol $\left(65^{\circ} \mathrm{C} ; \mathrm{pH} 4.5\right)$ (Ambion) and $400 \mu \mathrm{l}$ of chloroform-isoamyl alcohol (24:1; Sigma, St Louis, MO, USA) were added to the supernatant. These tubes were then mixed on a Labquake rotator (Barnestead/Thermolyne, Dubuque, IA, USA) for $10 \mathrm{~min}$ and centrifuged at $16100 \mathrm{~g}$ for $5 \mathrm{~min}$. The aqueous layer was removed and transferred to new $2 \mathrm{ml}$ screw cap tubes, and $600 \mu \mathrm{l}$ of hot acidic $\left(65^{\circ} \mathrm{C}\right.$; $\mathrm{pH}$ 4.5) phenol (Ambion) and $400 \mu \mathrm{l}$ of chloroformisoamyl alcohol (24:1; Sigma) were added. Tubes were mixed on a rotator for $5 \mathrm{~min}$ and centrifuged at $16100 \mathrm{~g}$ for $10 \mathrm{~min}$. The aqueous layer was removed again and transferred to a new tube, and $100 \mu \mathrm{l}$ of $5 \mathrm{M}$ ammonium acetate (Ambion), $20 \mu \mathrm{l}$ of $5 \mathrm{mg} \mathrm{ml}^{-1}$ glycogen (Ambion) and $1 \mathrm{ml}$ of cold $\left(-20^{\circ} \mathrm{C}\right)$ isopropanol (Sigma) were added.

Nucleic acids were precipitated at $-30^{\circ} \mathrm{C}$ for $1 \mathrm{~h}$ and pelleted by centrifugation at $16100 \mathrm{~g}$ for $30 \mathrm{~min}$. The pellet was then cleaned with cold $\left(-20^{\circ} \mathrm{C}\right) 70 \%$ ethanol, dried and resuspended in sterile diethylpyrocarbonate-treated water (Ambion). The resuspended pellets were combined and cleaned with the RNeasy RNA cleanup kit (Qiagen, Valencia, CA, USA) according to the manufacturer's instructions. The RNA cleanup product was then treated with DNA-free DNase (Ambion) according to the manufacturer's instructions.

High-quality RNA was extracted from these culture samples. All samples had $A_{260} / A_{280}$ ratios of 1.8-2.0, indicating that they were of high purity (Ausubel et al., 1990). In order to ensure that RNA samples were not contaminated with DNA, PCR amplification with primers targeting the 16S rRNA gene was conducted on RNA samples that had not undergone reverse transcription.

\section{Microarray analysis}

Whole-genome microarray hybridizations were carried out by Roche NimbleGen, Inc (Madison, WI, USA). The TransPlex Whole Transcriptome Amplification Kit (Sigma) was used to amplify RNA before transcriptomic analyses. RNA was obtained from three biological replicates, and triplicate technical replicates were conducted for microarray analyses. All cDNA samples were chemically labeled with Cy3 and hybridized by Nimblegen. The oligonucleotide microarrays used in this study were designed based on preliminary genome sequence data of $F$. placidus (accession number NC_013849) obtained from the
DOE Joint Genome Institute JGI website (http:// www.jgi.doe.gov).

A complete record of all oligonucleotide sequences used and raw and statistically treated data files is available in the NCBI Gene Expression Omnibus database (GEO data series numbers: GSE26421 (benzoate vs acetate), GSE26423 (phenol vs acetate) and GSE28549 (phenol vs benzoate).

Results from microarray hybridizations were analyzed with the software Array 4 Star (DNASTAR, Madison, WI, USA). $P$-values were determined with $t$-Student analysis. A gene was considered differentially expressed only if the $P$-value was $\leqslant 0.01$.

\section{Quantitative RT-PCR}

Primer pairs used for qRT-PCR analysis of gene transcript abundance are provided in Supplementary Table 1. All primers were purchased from Eurofins MWG Operon (Huntsville, AL, USA) and designed according to the manufacturer's specifications (amplicon size 100-200 bp). Representative products from each of these primer sets were verified by sequencing clone libraries.

Several different housekeeping genes were analyzed as potential external controls. The housekeeping genes topR, which encodes the DNA topoisomerase reverse gyrase; gyrA, which codes for the $\alpha$ subunit of DNA topoisomerase; and $m e t G$, which codes for methionyltRNA synthetase were tested. Expression of these three genes by $F$. placidus was stable under a variety of growth rates and conditions and none of them was differentially expressed in any of the microarray studies. Previous studies have used both met $G$ and gyrA as controls for qRT-PCR analyses (Takle et al., 2007; Theis et al., 2007; Henssge et al., 2009). A DuraScript enhanced avian RT single-strand synthesis kit (Sigma) was used to generate cDNA as previously described (Holmes et al., 2004).

For clone library construction, PCR products were purified with the Gel Extraction Kit (Qiagen), and clone libraries were constructed with a TOPO TA cloning kit, version M (Invitrogen, Carlsbad, CA, USA) according to the manufacturer's instructions. In all, 100 plasmid inserts from each clone library were sequenced with the M13F primer at the University of Massachusetts Sequencing Facility.

Once the appropriate cDNA fragments were generated by RT-PCR, qRT-PCR amplification and detection were performed with the 7500 Real-Time PCR System (Applied Biosystems, Carlsbad, CA, USA). Optimal qRT-PCR conditions were determined using the manufacturer's guidelines. Each PCR mixture consisted of a total volume of $25 \mu \mathrm{l}$ and contained $1.5 \mu \mathrm{l}$ of the appropriate primers (stock concentrations, $15 \mu \mathrm{M}$ ), and $12.5 \mu \mathrm{l}$ Power SYBR Green PCR Master Mix (Applied Biosystems). Standard curves covering eight orders of magnitude were constructed with serial dilutions of known amounts of purified cDNA quantified with a NanoDrop ND-1000 spectrophotometer at an absorbance of $260 \mathrm{~nm}$. 
qRT-PCR analyses were conducted with 36 different genes that were differentially expressed during growth on either phenol or benzoate compared with acetate. Triplicate biological and technical replicates were done for each of these genes. The number of mRNA transcripts expressed by these genes was normalized against the average number of mRNA transcripts from the constitutively expressed housekeeping genes topR, met $G$ and gyr $A$ (Supplementary Tables 2 and 3). When comparisons were made between microarray and qRT-PCR studies, similar results were obtained for all three housekeeping genes $\left(R^{2}=0.71,0.84\right.$ and 0.84$)$ (Supplementary Figure 1).

\section{Results and discussion}

\section{Strategy for pathway reconstruction}

In order to determine whether the $F$. placidus genome contained genes with homology to genes known to be involved in anaerobic benzoate and phenol metabolism in other microorganisms, comparisons were made to the characterized aromatic degradation pathway genes in T. aromatica (Breese et al., 1998; Breinig et al., 2000), Aromatoleum aromaticum EbN1 (Rabus et al., 2005), G. metallireducens (Wischgoll et al., 2005; Butler et al., 2007; Schleinitz et al., 2009) and R. palustris (Egland et al., 1997; Harwood et al., 1999). Despite the substantial phylogenetic distance between $F$. placidus and these mesophilic benzoate- and phenol-degrading bacteria, candidate genes for benzoate and phenol metabolism with high homology to those in the mesophilic bacteria could be identified in the $F$. placidus genome (Supplementary Tables 4 and 5). Many of the genes associated with benzoate metabolism are localized within two gene clusters, whereas genes associated with phenol metabolism are found in a third cluster (Figure 4). This gene organization resembles those previously described in bacteria (Carmona et al., 2009). Since F. placidus is the only hyperthermophilic archaeon known to degrade aromatic compounds, it was of interest to study these pathways in more detail. Therefore, transcriptomic studies were conducted with microarray and qRT-PCR analyses. These studies revealed that $F$. placidus utilizes the benzoate-CoA ligation pathway for anaerobic benzoate oxidation and the phenylphosphate/phenylcarboxylase pathway for anaerobic phenol oxidation. In addition, once phenol is converted to benzoyl-CoA, it utilizes the same benzoate-CoA ligation pathway as benzoate. Further evaluation of the pathways was based on additional analysis of gene sequences and gene expression patterns as described below.

Whole-genome microarray comparisons of $\mathrm{F}$. placidus cells grown on benzoate, phenol and acetate

In order to gain insight into the physiology of $F$. placidus cells growing with either benzoate or phenol provided as the sole carbon source, three different whole-genome DNA microarray studies were done; benzoate vs acetate, phenol vs acetate and phenol vs benzoate. In the microarray experiment comparing benzoate- and acetate-grown cells, a total of 450 genes (245 up-regulated, 205 downregulated) exhibited at least a twofold change in expression $(P$-value cutoff $=0.01)$. Many of the genes that were significantly up-regulated were involved in aromatics degradation (18 genes), energy metabolism (48 genes) or coded for hypothetical or unknown proteins (82 genes) (Supplementary Table 6). Analysis of the microarray comparing phenol- and acetate-grown cells indicated that 161 genes were differentially expressed (102 upregulated, 59 down-regulated) under these two conditions. Among the 102 genes that were up-regulated during growth on phenol, 18 of them coded for proteins involved in aromatics degradation, 12 coded for proteins involved in energy metabolism and 42 were annotated as coding for hypothetical or unknown proteins. When phenolgrown cells were compared with benzoate-grown cells, 38 genes (10 up-regulated, 28 down-regulated) exhibited at least a fourfold difference and $60 \%$ of the up-regulated genes coded for proteins were involved in phenol degradation.

\section{Benzoate-CoA ligase}

BCL catalyzes the first step of anaerobic benzoate metabolism in mesophilic bacteria and there are 12 genes in the F. placidus genome annotated as AMPdependent synthetase/ligase genes that could potentially represent BCLs (Supplementary Table 7). Eight of the 12 are most similar to BCLs (Ferp_0091, Ferp_2180, Ferp_1044, Ferp_1567, Ferp_2239, Ferp_0083, Ferp_1484 and Ferp_0788). The other four (Ferp_1228, Ferp_1946, Ferp_0992 and Ferp_2312) are most similar to characterized phenylacetate-CoA ligases. Three of the putative BCLs had higher transcript abundance in cells grown on benzoate vs acetate: Ferp_1044, Ferp_2180 and Ferp_0788. One of the putative phenylacetate-CoA ligases, Ferp_1228, also had 2.3 times more mRNA transcripts during growth on benzoate (Supplementary Table 7).

Ferp_1044 appears to be the most likely candidate for BCL because it is located within cluster 1 (Figure 4), with other genes thought to be associated with benzoate metabolism. It has high (44\%) similarity to the BCL from T. aromatica (Supplementary Table 7), and is the most highly up-regulated during growth on benzoate among the candidate BCL genes. However, in the absence of a genetic system to enable gene deletions, it cannot be definitively ruled out that one or more of the other putative BCLs might also have a role in benzoate metabolism.

Duplicate BCLs have been reported for facultative anaerobic benzoate-degrading microorganisms, 


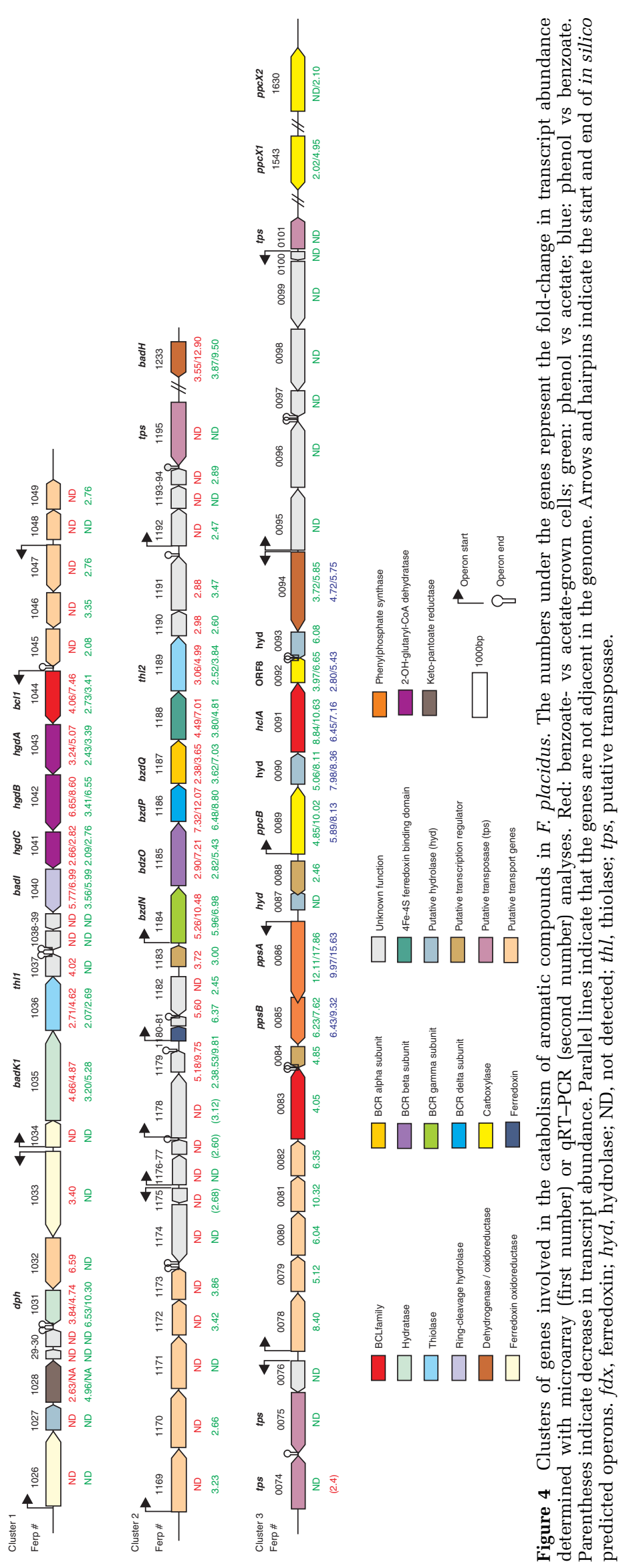


Azoarcus evansii and A. aromaticum, one associated with aerobic metabolism and another with anaerobic metabolism of benzoate (Gescher et al., 2002; Rabus et al., 2005; Carmona et al., 2009). However, F. placidus is a strict anaerobe (Hafenbradl et al., 1996), and no genes for aerobic metabolism of benzoate via hydroxylation or the BOX pathway (Zaar et al., 2001; Gescher et al., 2002; Risso et al., 2009) were apparent in the genome. Multiple anaerobic BCLs have also been detected in other organisms. $R$. palustris has three ligases that could potentially catalyze benzoyl-CoA formation anaerobically (Egland et al., 1995). There are also multiple potential ligases in the strict anaerobe $S$. aciditrophicus (four potential genes), but only one is associated with a benzoate cluster (McInerney et al., 2007). In G. metallireducens, there are also four potential genes, but only Gmet_2143 (bamY) is associated with a benzoate catabolism gene cluster (Butler et al., 2007).

\section{Benzoyl-CoA reductase}

Surprisingly, there are no genes in $F$. placidus for a class II BCR, which has been proposed to catalyze the next step in benzoate metabolism in all known strict anaerobic bacteria (Löffler et al., 2010). However, there is a set of genes (Ferp_1184-1187) that encodes proteins with high homology to each of the four subunits of the class I bzd-type BCR complex (BzdNOPQ) (Supplementary Table 4) first described in Azoarcus spp. (Lopez Barragan et al., 2004). All four of these subunits are most similar to those found in $A$. aromaticum EbN1 (42-55\% identity, $63-72 \%$ similarity). Evidence that these genes are involved in benzoate metabolism includes their localization in a cluster of other genes associated with benzoate metabolism (Figure 4) and increased expression of each of these genes during growth on benzoate vs growth on acetate (Figure 2; Supplementary Table 4). There was also an increase in the transcript abundance for these genes during growth on phenol vs growth on acetate, consistent with the expectation that once phenol is metabolized to benzoyl-CoA (Figure 3; Supplementary Table 5), further metabolism follows the same pathway as shown for benzoate metabolism (Figure 2).

BCRs use low potential ferredoxin proteins as electron donors for the initial dearomatization step (Boll and Fuchs, 1998; Harwood et al., 1999). Multiple genes coding for ferredoxin proteins were up-regulated during growth on benzoate compared with acetate in $F$. placidus (Supplementary Table 8), but none of these ferredoxin genes were homologous to the low potential ferredoxins found in T. aromatica (Boll and Fuchs, 1998) or $R$. palustris (BadB) (Boll and Fuchs, 1998; Harwood et al., 1999). However, a gene coding for a putative ferredoxin that was up-regulated fivefold according to microarray studies during growth on benzoate (Ferp_1180) is also associated with other benzoate degradation genes, including those encoding BCR, found in cluster 2 (Figure 4).

Enzymes involved in the regeneration of the reduced ferredoxin have been identified in both $R$. palustris and T. aromatica (Boll and Fuchs, 1998; Egland and Harwood, 1999; Dorner and Boll, 2002). In R. palustris, a putative nicotinamide adenine dinucleotide phosphate quinone oxidoreductase (BadC) is involved in ferredoxin regeneration (Egland and Harwood, 1999; Carmona et al., 2009); however, a homolog for this gene is not present in the F. placidus genome. In T. aromatica, 2-oxoglutarate:ferredoxin reductase from the citric acid cycle is responsible for regeneration of the reduced ferredoxin (Dorner and Boll, 2002). The $F$. placidus genome contains genes that could code for 2-oxoglutarate:ferredoxin oxidoreductase in benzoate cluster 1 . Both the $\alpha$ and $\beta$ subunits (Ferp_1033 and Ferp_1034) of this enzyme are found within this cluster and the $\alpha$ subunit is up-regulated 3.4-fold in benzoate-grown cells (Figure 4; Supplementary Table 9).

\section{Formation of 3-hydroxypimeloyl-CoA}

After the formation of cyclohex-1,5-diene-1-carboxylCoA by BCR, a series of reactions (addition of a molecule of water to a double bond, dehydrogenation and hydrolytic ring cleavage) generate a $\mathrm{C}_{7}$-dicarboxyl-CoA compound (Carmona et al., 2009). Two slightly different versions of these reactions have been described. One in $R$. palustris (Harwood et al., 1999; Gibson and Harwood, 2002) and an alternative pathway described in T. aromatica (Breese et al., 1998) and Azoarcus sp. (Lopez Barragan et al., 2004), which appears to be conserved in all previously described anaerobic benzoate-degrading heterotrophs (Carmona et al., 2009).

There is little evidence for this later pathway in $F$. placidus, its genome does not contain homologs for the key enzymes 6-hydroxycyclohex-1-ene-1carbonyl-CoA dehydrogenase (Had) and 6-oxocyclohex-1-ene-1-carbonyl-CoA hydratase (Oah). Instead, the sequence of water addition to a double bond followed by dehydrogenation and hydrolytic ring cleavage is more similar to that found in the autotroph R. palustris (Figure 2). This is somewhat unexpected because the BCR of $F$. placidus is more closely related to that of microorganisms using the T. aromatica/Azoarcus sp. pathway.

The mechanism for the formation of cyclohex-1ene-1-carboxyl-CoA, the first unique step in the $R$. palustris pathway (Figure 2), has yet to be definitely determined, but it has been proposed that this results from additional activity of the BCR, with the low-potential electron donor ferredoxin (BadB) participating in multiple catalytic cycles of reduction and oxidation (Egland et al., 1997). F. placidus has several ferredoxin genes that could potentially act as electron donors that were significantly upregulated during growth on benzoate (Supplementary Table 8), including Ferp_1180, which as noted 
above is within one of the clusters of benzoatedegradation genes. In $R$. palustris, the hydratase BadK converts cyclohex-1-ene-1-carboxyl-CoA to 2-hydroxycyclohexane-1-carboxyl-CoA. There are two putative BadK homologs in F. placidus (badK1, Ferp_1035 and badK2, Ferp_1942), but only Ferp_1035 is significantly up-regulated during growth with benzoate and it is located within one of the clusters of benzoate-degradation genes.

The $F$. placidus genome also contains a likely candidate for the next enzyme in the $R$. palustris pathway, 2-hydroxycyclohexane-1-carboyxl-CoA dehydrogenase (BadH). Ferp_1233, a $\mathrm{NAD}^{+}$-dependent secondary alcohol dehydrogenase, is predicted to fulfill this function. Ferp_1233 is not located in either of the two benzoate-specific clusters. Instead, it is associated with a cluster that contains genes potentially involved in the degradation of phenylacetate (Ferp 1228-1233), another aromatic compound that feeds into the benzoate-CoA ligation pathway in bacteria. All of the genes from this cluster were significantly up-regulated during growth on both benzoate and phenol compared with growth on acetate (Supplementary Tables 9 and 10).

Ferp_1040 is predicted to code for the ringcleaving hydrolase, BadI. This gene is located in a cluster of benzoate-specific genes (Figure 4) and transcripts for this gene were significantly higher during growth on benzoate or phenol vs growth on acetate (Figure 2). Ferp_1040 also has homology (30\% identity, $44 \%$ similarity) to Oah, an enzyme from the alternative pathway for benzoate metabolism in T. aromatica. However, the amino-acid sequence of Ferp_1040 is more similar to BadI (33\% identity, 51\% similarity), and when Oah, BadI and Ferp_1040 amino-acid sequences were aligned, a 49-bp deletion was apparent in BadI that was also present in Ferp_1040 (Supplementary Figure 2). These results suggest that Ferp_1040 encodes BadI. In R. palustris, the pimeloyl-CoA produced by BadI is subsequently transformed into glutaryl-CoA by a series of reactions catalyzed by enzymes encoded in the pimFABCD operon (Harrison and Harwood, 2005). Such an operon is not present in F. placidus. The large and small subunits of the pimeloyl-CoA dehydrogenase (PimCD) are best represented by Ferp_1566 and Ferp_1579, 43\% and 47\% similar to PimC and PimD from $R$. palustris, respectively (Figure 2; Supplementary Table 4). These genes are not associated with any of the aromatic-metabolism clusters. This coupled with the finding that their mRNA transcripts were not highly up-regulated in benzoate-grown cultures makes this assignment the most tenuous of all the genes predicted to be part of the benzoate degradation pathway.

The next step is hydration of the double bond of 2,3-didehydro-pimeloyl-CoA to form 3-hydroxypimeloyl-CoA. A possible candidate to catalyze this reaction is the product of the gene Ferp_1031, located in cluster 1 (Figure 4). Its expression is up-regulated during growth on benzoate and phenol and it is highly homologous to enoyl-CoA hydratases in other organisms.

\section{Initial steps in phenol metabolism}

Sequence analysis indicated that in $F$. placidus, phenol is activated by the phenylphosphate/phenylcarboxylase pathway. Genes coding for the A and $\mathrm{B}$ subunits of phenylphosphate synthase (ppsAB, Ferp_0085-86) and phenylphosphate carboxylase ( $р$ p $\bar{B}$, Ferp_0089); together with a 4-hydroxybenzoate-CoA ligase (hclA, Ferp_0091) were found in the genome located within a distinct cluster (Figure 4).

Transcript levels for Ferp_0085, Ferp_0086 and Ferp_0089, as well as other genes in the phenolspecific gene cluster, were higher during growth on phenol vs acetate and phenol vs benzoate (Figures 3 and 4), suggesting that this is the preferred pathway of phenol catabolism in $F$. placidus. Further evidence that 4-hydroxybenzoate is formed by the phosphorylation and carboxylation of phenol was provided by the fact that the intermediate phenylphosphate was detected in phenol-grown cells via thin layer chromatography and high performance liquid chromatography (Supplementary Figure 3).

The next step in phenol metabolism, synthesis of 4-hydroxybenzoyl-CoA, is most likely catalyzed by the product of Ferp_0091. This protein belongs to the BCL family, and is most similar to characterized benzoate- and 4-hydroxybenzoate-CoA ligases from other benzoate- and phenol-degrading organisms (Supplementary Table 7), particularly BclA from T. aromatica (40\% identity, $57 \%$ similarity) and HbaA from $R$. palustris (36\% identity, 58\% similarity). Expression of Ferp_0091 was up-regulated during growth on phenol (Figure 3) but not during growth on benzoate, suggesting that Ferp_0091 is a phenol-specific gene that actually codes for 4hydroxybenzoate-CoA ligase, hclA (Figure 3).

The last step in the activation of phenol, reductive dehydroxylation of 4-hydroxybenzoyl-CoA to benzoyl-CoA, is catalyzed by the 4-hydroxybenzoyl-CoA reductase (HbaBCD). This enzyme has been studied in R. palustris (Gibson et al., 1997) and has homologs in anaerobic phenol-degrading organisms such as $G$. metallireducens, T. aromatica and A. aromaticum EbN1, but is not present in the $F$. placidus genome. The enzyme performing this function in $F$. placidus is not known. However, it is highly likely that phenol metabolism proceeds via the formation of benzoyl-CoA as the genes involved in benzoate metabolism were highly up-regulated in cells grown on phenol vs acetate (Figure 3), and were expressed at levels comparable to those in cells grown on benzoate (Supplementary Table 11).

An alternative strategy for anaerobic phenol metabolism in which phenol is directly carboxylated to 4-hydroxybenzoate has previously been reported (Zhang and Wiegel, 1994). Two genes in the $F$. placidus genome that encode UbiD-like carboxylases could serve this function (Ferp_1543 
and Ferp_1630). Ferp_1543 (PpcX1) was up-regulated when phenol-grown cells were compared with acetate-grown cells but not when compared with benzoate-grown cells. Ferp_1630 (PpcX2), on the other hand, was not differentially expressed under either condition (Figure 3; Supplementary Table 5). Furthermore, neither of these genes was associated with the phenol-specific gene cluster that contains the other genes involved in metabolizing the 4-hydroxybenzoate produced from this potential reaction.

The organization of genes in the phenol cluster is similar to that found in bacteria and the presence of two genes coding for putative transposases (Ferp_0074 and Ferp_0101) flanking the phenol degradation cluster (Figure 4) are consistent with recent genetic mobility. In contrast, only one of the two benzoate clusters had a transposase and only at one end of the cluster.

Other genes differentially expressed during growth with aromatic compounds

The clusters associated with aromatic metabolism contain additional genes with a possible role in benzoate and phenol degradation. For example, Ferp_1028, found in the first benzoate-specific gene cluster (Figure 4) codes for ketopantoate reductase, an enzyme involved in the biosynthesis of CoA, a critical cofactor in the degradation of aromatic compounds. Transcripts for this gene were significantly higher in benzoate and phenol-grown cells vs acetate-grown cells (Figure 4).

The products of Ferp_1041-1043 have some homology to BCRs $(58 \%, 45 \%$ and $46 \%$ similar to the $\alpha, \beta$ and $\gamma$ subunits of BCR from T. aromatica). These genes are also localized in the first cluster of genes with clear involvement in benzoate metabolism, and the expression of these genes is significantly higher during growth on benzoate or phenol vs growth on acetate (Figure 4). However, previously described BCRs have four subunits (Carmona et al., 2009), which suggests that Ferp_1041-1043 may code for an enzyme complex with an alternative function. Comparison to previously sequenced organisms suggests that these genes might encode a 2-hydroxyglutaryl-CoA dehydratase (Hgd) similar to that found in the fermentative bacterium, Clostridium symbiosum. Ferp_1041 is $66 \%$ similar to this enzyme's activator subunit (HgdC), and Ferp_1042 and Ferp_1043 are ca. 45\% similar to this enzyme's $\alpha$ and $\beta$ subunits (HgdAB). This enzyme is usually involved in the fermentation of amino acids and has been shown to have a small but significant homology to BCRs from T. aromatica and $R$. palustris, as well as to putative proteins from several Archaea (Hans et al., 1999). Given these ambiguities, further evaluation is required before an assignment of a specific role for the proteins coded by Ferp_1041-1043 in benzoate metabolism can be made.
In cluster 2, Ferp_1181-1183 were up-regulated during growth on both benzoate and phenol. These genes code for hypothetical proteins of unknown function, and Ferp_1181 appears to be unique to F. placidus (Supplementary Tables 9 and 10). In cluster 3, Ferp_0092 encodes a putative phenol carboxylase (PpcY) that is associated with anaerobic phenol degradation in other organisms such as A. aromaticum EbN1, T. aromatica, G. metallireducens and G. daltonii (Schleinitz et al., 2009). Its closest relative is Gmet_2105 (58\% identity/78\% similarity). This gene was first identified in T. aromatica and is referred to as ORF8. Although its expression is up-regulated during growth on phenol vs acetate (fourfold) and phenol vs benzoate (2.80-fold), its role in phenol degradation is unclear (Breinig et al., 2000). The roles of Ferp_0090 and Ferp_0094, also up-regulated during growth on phenol, are unknown as well.

There are at least two other clusters of genes whose expression was up-regulated during growth on aromatic compounds; Ferp_1227-1233 and Ferp_1683-1689. Ferp_1227-1233 includes some genes coding for enzymes associated with aromatic metabolism; Ferp_1228 encodes a putative phenylacetate-CoA ligase, Ferp_1233 encodes BadH and Ferp_1230-1232 code for redox proteins. The genes in the Ferp_1683-1689 cluster code primarily for redox proteins. The role of the majority of genes in this cluster in benzoate and phenol degradation is uncertain. However, the fact that they are up-regulated during growth on both aromatic compounds suggests that they belong to a shared pathway, possibly the lower steps of degradation that lead to the formation of acetyl-CoA.

\section{Implications}

These results suggest that although $F$. placidus is a hyperthermophilic archaeon, it metabolizes benzoate and phenol via pathways previously described in mesophilic bacteria. However, several unifying features of benzoate metabolism that have been observed in the mesophilic bacteria that have been studied to date, do not apply to F. placidus.

Most surprising is the finding that $F$. placidus lacks genes for the ATP-independent class II BCRs that have previously been found in all strict anaerobes. It has been postulated that strict anaerobes must use ATP-independent class II BCRs because the consumption of two ATPs with class I BCRs would preclude a sufficient net gain of energy to support growth under strict anaerobic conditions (Kung et al., 2009, 2010; Löffler et al., 2010). However, the fact that $F$. placidus is able to metabolize benzoate anoxically with an ATPconsuming class I BCR indicates that this rule does not apply to all anaerobic organisms and might be restricted to mesophilic bacteria. The energy available for anaerobic oxidation of benzoate coupled to $\mathrm{Fe}(\mathrm{III})$ oxide reduction at $25^{\circ} \mathrm{C}(-92 \mathrm{~kJ} /$ electron 
equivalent) is comparable to that available at $85{ }^{\circ} \mathrm{C}$ (-99kJ/electron equivalent) (Tor and Lovley, 2001), indicating that this alone is not sufficient to account for differences in the metabolic pathways utilized by $F$. placidus and a mesophilic bacterium such as G. metallireducens.

In addition to providing further insights into the metabolism of aromatic compounds in F. placidus, this study has identified key genes whose expression can be indicative of ongoing metabolism of aromatic compounds at high temperatures. The physiological characteristics of hyperthermophilic microorganisms are often used to infer aspects of evolution of microbial physiology as well as for understanding reactions that might have been prevalent on early Earth. Thus, further study of the diverse microbes capable of anaerobically oxidizing aromatic compounds at high temperatures and their enzymes seems warranted.

\section{Acknowledgements}

We thank Julia Krushkal and Yanhua Qu for their contribution with operon analysis, Muktak Aklujkar for helpful discussions on this manuscript and Joy Ward for her excellent technical support. This research was supported by the Office of Science (BER), U.S. Department of Energy, Cooperative Agreement No. DE-FC02-02ER63446.

\section{References}

Ausubel FM, Brent R, Kingston RE, Moore DD, Seidman JG, Smith JA et al. (1990). Current Protocols in Molecular Biology. Greene: New York.

Balch WE, Fox GE, Magrum LJ, Woese CR, Wolfe RS. (1979). Methanogens: reevaluation of a unique biological group. Microbiol Rev 43: 260-296.

Bazylinski DA, Wirsen CO, Jannasch HW. (1989). Microbial utilization of naturally occurring hydrocarbons at the guaymas basin hydrothermal vent site. Appl Environ Microbiol 55: 2832-2836.

Boll M. (2005). Dearomatizing benzene ring reductases. J Mol Microbiol Biotechnol 10: 132-142.

Boll M, Fuchs G. (1995). Benzoyl-coenzyme a reductase (dearomatizing), a key enzyme of anaerobic aromatic metabolism. Eur J Biochem 234: 921-933.

Boll M, Fuchs G. (1998). Identification and characterization of the natural electron donor ferredoxin and of FAD as a possible prosthetic group of benzoyl-CoA reductase (dearomatizing), a key enzyme of anaerobic aromatic metabolism. Eur J Biochem 251: 946-954.

Breese K, Boll M, Alt-Morbe J, Schagger H, Fuchs G. (1998). Genes coding for the benzoyl-CoA pathway of anaerobic aromatic metabolism in the bacterium Thauera aromatica. Eur J Biochem 256: 148-154.

Breinig S, Schiltz E, Fuchs G. (2000). Genes involved in anaerobic metabolism of phenol in the bacterium Thauera aromatica. J Bacteriol 182: 5849-5863.

Butler JE, He Q, Nevin KP, He Z, Zhou J, Lovley DR. (2007). Genomic and microarray analysis of aromatics degradation in Geobacter metallireducens and comparison to a Geobacter isolate from a contaminated field site. BMC Genomics 8: 180.
Carmona M, Zamarro MT, Blazquez B, Durante-Rodriguez G, Juarez JF, Valderrama JA et al. (2009). Anaerobic catabolism of aromatic compounds: a genetic and genomic view. Microbiol Mol Biol Rev 73: 71-133.

Coates JD, Lonergan DJ, Philips EJ, Jenter H, Lovley DR. (1995). Desulfuromonas palmitatis sp. nov., a marine dissimilatory $\mathrm{Fe}(\mathrm{III})$ reducer that can oxidize longchain fatty acids. Arch Microbiol 164: 406-413.

Culotta L, Gianguzza A, Mannino MR, Orecchio S. (2007). Polycyclic aromatic hydrocarbons (pah) in Vulcano Island (aeolian archipelago) mud utilized for therapeutic purpose. Polycycl Aromat Comp 27: 281-294.

Dorner E, Boll M. (2002). Properties of 2-oxoglutarate:ferredoxin oxidoreductase from Thauera aromatica and its role in enzymatic reduction of the aromatic ring. J Bacteriol 184: 3975-3983.

Egland PG, Gibson J, Harwood CS. (1995). Benzoatecoenzyme A ligase, encoded by $\operatorname{bad} A$, is one of three ligases able to catalyze benzoyl-coenzyme A formation during anaerobic growth of Rhodopseudomonas palustris on benzoate. J Bacteriol 177: 6545-6551.

Egland PG, Harwood CS. (1999). BadR, a new MarR family member, regulates anaerobic benzoate degradation by Rhodopseudomonas palustris in concert with AadR, an Fnr family member. J Bacteriol 181: 2102-2109.

Egland PG, Pelletier DA, Dispensa M, Gibson J, Harwood CS. (1997). A cluster of bacterial genes for anaerobic benzene ring biodegradation. Proc Natl Acad Sci USA 94: 6484-6489.

Elshahed MS, McInerney MJ. (2001). Benzoate fermentation by the anaerobic bacterium Syntrophus aciditrophicus in the absence of hydrogen-using microorganisms. Appl Environ Microbiol 67: 5520-5525.

Gescher J, Zaar A, Mohamed M, Schagger H, Fuchs G. (2002). Genes coding for a new pathway of aerobic benzoate metabolism in Azoarcus evansii. J Bacteriol 184: 6301-6315.

Gibson J, Dispensa M, Harwood CS. (1997). 4-Hydroxybenzoyl coenzyme A reductase (dehydroxylating) is required for anaerobic degradation of 4-hydroxybenzoate by Rhodopseudomonas palustris and shares features with molybdenum-containing hydroxylases. J Bacteriol 179: 634-642.

Gibson J, Harwood CS. (2002). Metabolic diversity in aromatic compound utilization by anaerobic microbes. Annu Rev Microbiol 56: 345-369.

Goetz FE, Jannasch HW. (1993). Aromatic hydrocarbondegrading bacteria in the petroleum-rich sediments of the guaymas basin hydrothermal vent site: preference for aromatic carboxylic acids. Geomicrobiol J 11: 1-18.

Hafenbradl D, Keller M, Dirmeier R, Rachel R, Rossnagel P, Burggraf S et al. (1996). Ferroglobus placidus gen. nov., sp. nov., A novel hyperthermophilic archaeum that oxidizes $\mathrm{Fe}^{2+}$ at neutral $\mathrm{pH}$ under anoxic conditions. Arch Microbiol 166: 308-314.

Hans M, Sievers J, Müller U, Bill E, Vorholt JA, Linder D et al. (1999). 2-Hydroxyglutaryl-CoA dehydratase from Clostridium symbiosum. Eur J Biochem 265: 404-414.

Harrison FH, Harwood CS. (2005). The pimFABCDE operon from Rhodopseudomonas palustris mediates dicarboxylic acid degradation and participates in anaerobic benzoate degradation. Microbiology 151: 727-736.

Harwood CS, Burchhardt G, Herrmann H, Fuchs G. (1999). Anaerobic metabolism of aromatic compounds via the benzoyl-CoA pathway. FEMS Microbiol Rev 22: 439-458. 
Henssge U, Do T, Radford DR, Gilbert SC, Clark D, Beighton D. (2009). Emended description of Actinomyces naeslundii and descriptions of Actinomyces oris sp nov and Actinomyces johnsonii sp nov., previously identified as Actinomyces naeslundii genospecies 1, 2 and WVA 963. Int J Syst Evol Microbiol 59: 509-516.

Holmes DE, Nevin KP, Lovley DR. (2004). In situ expression of nifD in Geobacteraceae in subsurface sediments. Appl Environ Microbiol 70: 7251-7259.

Kashefi K, Holmes DE, Lovley DR, Tor JM. (2000). 5th Ridge-Theoretical-Institute on the Subsurface Biosphere at Mid-Ocean Ridges. Wilcock WSD, DeLong EF, Kelley DS, Baross JA and Cary SC (eds) Big Sky: MT, pp 199-211.

Krushkal J, Yan B, DiDonato LN, Puljic M, Nevin KP, Woodard TL et al. (2007). Genome-wide expression profiling in Geobacter sulfurreducens: identification of Fur and RpoS transcription regulatory sites in a relGsu mutant. Funct Integr Genomics 7: 229-255.

Kung JW, Baumann S, von Bergen M, Muller M, Hagedoorn PL, Hagen WR et al. (2010). Reversible biological Birch reduction at an extremely low redox potential. J Am Chem Soc 132: 9850-9856.

Kung JW, Löffler C, Dörner K, Heintz D, Gallien S, Van Dorsselaer A et al. (2009). Identification and characterization of the tungsten-containing class of benzoyl-coenzyme A reductases. Proc Natl Acad Sci USA 106: 17687-17692.

Lack A, Fuchs G. (1994). Evidence that phenol phosphorylation to phenylphosphate is the first step in anaerobic phenol metabolism in a denitrifying Pseudomonas sp. Arch Microbiol 161: 132-139.

Löffler C, Kuntze K, Vazquez JR, Rugor A, Kung JW, Böttcher A et al. (2010). Occurrence, genes and expression of the W/Se-containing class II benzoylcoenzyme A reductases in anaerobic bacteria. Environ Microbiol 13: 696-709.

Lopez Barragan MJ, Carmona M, Zamarro MT, Thiele B, Boll M, Fuchs G et al. (2004). The bzd gene cluster, coding for anaerobic benzoate catabolism, in Azoarcus sp. strain CIB. J Bacteriol 186: 5762-5774.

Lovley DR, Phillips EJP. (1988). Novel mode of microbial energy metabolism: organic carbon oxidation coupled to dissimilatory reduction of iron or manganese. Appl Environ Microbiol 54: 1472-1480.

Magot M, Ollivier B, Patel BK. (2000). Microbiology of petroleum reservoirs. Antonie Van Leeuwenhoek 77: 103-116.

Mahadevan R, Yan B, Postier B, Nevin KP, Woodard TL, $\mathrm{O}^{\prime}$ Neil $\mathrm{R}$ et al. (2008). Characterizing regulation of metabolism in Geobacter sulfurreducens through genome-wide expression data and sequence analysis. OMICS 12: 33-59.

Mangani F, Cappiello A, Capaccioni B, Martini M. (1991). Sampling and analysis of light hydrocarbons in volcanic gases. Chromatographia 32: 441-444.

McInerney MJ, Rohlin L, Mouttaki H, Kim U, Krupp RS, Rios-Hernandez L et al. (2007). The genome of Syntrophus aciditrophicus: life at the thermodynamic limit of microbial growth. Proc Natl Acad Sci USA 104: 7600-7605.
Merkel SM, Eberhard AE, Gibson J, Harwood CS. (1989). Involvement of coenzyme A thioesters in anaerobic metabolism of 4-hydroxybenzoate by Rhodopseudomonas palustris. J Bacteriol 171: 1-7.

Miller TL, Wolin MJ. (1974). A serum bottle modification of the Hungate technique for cultivating obligate anaerobes. Appl Microbiol 27: 985-987.

Peters F, Rother M, Boll M. (2004). Selenocysteinecontaining proteins in anaerobic benzoate metabolism of Desulfococcus multivorans. $J$ Bacteriol 186: 2156-2163.

Rabus R, Kube M, Heider J, Beck A, Heitmann K, Widdel F et al. (2005). The genome sequence of an anaerobic aromatic-degrading denitrifying bacterium, strain EbN1. Arch Microbiol 183: 27-36.

Risso C, Sun J, Zhuang K, Mahadevan R, DeBoy R, Ismail W et al. (2009). Genome-scale comparison and constraint-based metabolic reconstruction of the facultative anaerobic Fe(III)-reducer Rhodoferax ferrireducens. BMC Genomics 10: 447.

Schleinitz KM, Schmeling S, Jehmlich N, von Bergen M, Harms H, Kleinsteuber S et al. (2009). Phenol degradation in the strictly anaerobic iron-reducing bacterium Geobacter metallireducens GS-15. Appl Environ Microbiol 75: 3912-3919.

Schöcke L, Schink B. (1999). Energetics and biochemistry of fermentative benzoate degradation by Syntrophus gentianae. Arch Microbiol 171: 331-337.

Simoneit BRT, Lonsdale PF. (1982). Hydrothermal petroleum in mineralized mounds at the seabed of Guaymas Basin. Nature 295: 198-202.

Takle GW, Toth IK, Brurberg MB. (2007). Evaluation of reference genes for real-time RT-PCR expression studies in the plant pathogen Pectobacterium atrosepticum. BMC Plant Biol 7: 9.

Theis T, Skurray RA, Brown MH. (2007). Identification of suitable internal controls to study expression of a Staphylococcus aureus multidrug resistance system by quantitative real-time PCR. J Microbiol Meth 70: 355-362.

Tor JM, Kashefi K, Lovley DR. (2001). Acetate oxidation coupled to $\mathrm{Fe}(\mathrm{III})$ reduction in hyperthermophilic microorganisms. Appl Environ Microbiol 67: 1363-1365.

Tor JM, Lovley DR. (2001). Anaerobic degradation of aromatic compounds coupled to Fe(III) reduction by Ferroglobus placidus. Environ Microbiol 3: 281-287.

Tran HT, Krushkal J, Antommattei FM, Lovley DR, Weis RM. (2008). Comparative genomics of Geobacter chemotaxis genes reveals diverse signaling function. BMC Genomics 9: 471.

Wischgoll S, Heintz D, Peters F, Erxleben A, Sarnighausen $\mathrm{E}$, Reski $\mathrm{R}$ et al. (2005). Gene clusters involved in anaerobic benzoate degradation of Geobacter metallireducens. Mol Microbiol 58: 1238-1252.

Zaar A, Eisenreich W, Bacher A, Fuchs G. (2001). A novel pathway of aerobic benzoate catabolism in the bacteria Azoarcus evansii and Bacillus stearothermophilus. J Biol Chem 276: 24997-25004.

Zhang X, Wiegel J. (1994). Reversible conversion of 4-hydroxybenzoate and phenol by Clostridium hydroxybenzoicum. Appl Environ Microbiol 60: 4182-4185.

Supplementary Information accompanies the paper on The ISME Journal website (http://www.nature.com/ismej) 